\begin{tabular}{|l|l|l|l|l|l|l|}
\hline Rev. Intropica & ISSN 1794-161X & Vol. 12 & No. 2 & 143 - 159 & julio - diciembre de 2017 & Santa Marta, Colombia \\
\hline
\end{tabular}

\title{
APORTACIONES SOBRE EL CAMPO MAGNÉTICO: HISTORIA E INFLUENCIA EN SISTEMAS BIOLÓGICOS
}

\author{
CONTRIBUTIONS TO THE MAGNETIC FIELD: HISTORY AND INFLUENCE ON \\ BIOLOGICAL SYSTEMS
}

María Victoria CarbonelliD, Mercedes Flórez, Elvira Martinez y José Álvarez

\begin{abstract}
RESUMEN
Este artículo repasa la historia del magnetismo siguiendo un orden cronológico que comienza con la evolución del conocimiento científico en las primeras civilizaciones, después en Egipto y China, seguido de la antigua Grecia y Roma. Por último, se describen también la Edad Media y la Edad Moderna. Posteriormente, se comentan los hallazgos de los investigadores más importantes en el campo del electromagnetismo como son Oersted, Biot y Savart, Ampère, Sturgeon, Faraday, Lenz, Maxwell y Coulomb. Se resumen los principios básicos del electromagnetismo, con especial énfasis en la relación entre carga eléctrica y magnetismo. Asimismo, es parte esencial la relación entre campos magnéticos y sistemas biológicos, sobre todo semillas y plantas. Con la ayuda de una minuciosa recopilación de bibliografía, se tratan en detalle los efectos sobre diversas especies de plantas que tiene el campo magnético natural de la Tierra, como magnetismo natural, y de los causados por la aplicación de campos magnéticos estacionarios.
\end{abstract}

PALABRAS CLAVE: electricidad; magnetismo; germinación; tratamiento magnético

\begin{abstract}
This article reviews the history of magnetism following a chronological order, starting with the evolution of scientific knowledge regarding the topic in earlier civilizations, then moving to Egypt and China, later on to Ancient Greece and Rome, and ending at the Middle Ages and Early Modern period. The findings of prominent theoretical contributors to electromagnetism such as Oersted, Biot and Savart, Ampère, Sturgeon, Faraday, Lenz, Maxwell and Coulomb are discussed. The basics of magnetism --especially its relationship to electrical load-- are summarized. The interaction between magnetic fields and biological systems, plants and seeds above all, is highlighted as well. Based on an exhaustive bibliographic review, the effects of the magnetic field of the Earth as natural magnetism and those caused by the application of stationary magnetic fields on plant species are described in detail.
\end{abstract}

KEY WORDS: electricity; magnetism; germination; magnetic treatment

Dirección de los autores:

Universidad Politécnica de Madrid. Ciudad Universitaria s/n 28040 Madrid, España, Departamento de Ingeniería Agroforestal. ETS Ingeniería Agraria, Alimentaria y de Biosistemas; e-mail: victoria.carbonell@upm.es, ORCID: 0000-0002-8211-353X (M.V.C); e-mail: mercedesflorez@upm.es, (M. F); e-mail: elvira.martinez@upm.es, (E.M); e-mail: jose.alvarez.sanchez@upm.es, (J.A). 


\section{INTRODUCCIÓN}

El interés del ser humano por el fenómeno del magnetismo se remonta a las primeras civilizaciones; hay registros de por lo menos 600 años a.C. que evidencian el conocimiento de la electricidad estática (Buck y Hayt, 2006). El campo magnético que protege a la Tierra de la radiación y los vientos solares se formó hace 3450 millones de años, promoviendo la aparición de actividad biológica en el planeta (Tarduno et al., 2010). La intensidad del campo magnético terrestre es bastante débil y oscila entre 0,4 - 0,6 Gauss, dependiendo de la latitud (Álvarez, 2011).

Los campos magnéticos afectan a todos los seres vivos, motivo por el cual son objeto de investigación a nivel mundial. Por ejemplo, la orientación animal ha sido uno de los grandes misterios de la naturaleza. Una evidencia directa del mencionado efecto del magnetismo terrestre sobre los seres vivos es la existencia de ciertas algas y bacterias que utilizan el geomagnetismo (poseen cristales de magnetita alineados en largas cadenas llamadas magnetosomas) para orientarse. Igualmente, el comportamiento magnético de las bacterias que fue descubierto por Blakemore (1975). También se ha encontrado magnetita en el abdomen de abejas vivas y en el cráneo de pichones. Recientemente, al estudiar los mecanismos de migración de peces, se encontraron respuestas condicionadas por el campo magnético terrestre en el atún de aleta amarilla y se detectaron y caracterizaron cristales de magnetita provenientes de un tejido que se encuentra ligado a un hueso del cráneo (Tagüeña y Martina, 1997). Además, se cree que la magnetorrecepción pudo haber sido uno de los primeros sistemas sensoriales en evolucionar en el reino animal (Kirschvink y Walker, 2001) y ha servido de influencia para el diseño de dispositivos en el campo de la robótica (Mouritsen, 2001).

En los humanos, los campos magnéticos gobiernan ciertos aspectos del funcionamiento de las neuronas, y existe una controversia importante en cuanto a su influencia en la salud ante la posibilidad de que puedan existir consecuencias nocivas: los producidos por las líneas de alta tensión, las antenas de telefonía móvil, la tecnología o los electrodomésticos. Sin embargo, las aplicaciones controladas de estos campos son muy variadas y la ciencia del magnetismo resulta esencial en nuestra tecnología como medio ideal de almacenamiento de datos en cintas magnéticas, discos magnéticos y burbujas magnéticas, además de sus aplicaciones 144 médicas: equipos de radiodiagnóstico, magnetoterapia o el diseño de equipos de radioterapia de alta energía para el tratamiento de enfermedades oncológicas (Pérez y Brady, 1998).

Desde un enfoque estrictamente agrícola, en el siglo pasado se comenzaron a realizar investigaciones con el fin de determinar si un campo magnético cambia la velocidad de germinación y desarrollo de las plantas; en la bibliografía se encuentran casos tanto de estimulación como de inhibición de crecimiento al aplicar campos magnéticos sobre semillas de diversas familias. Esto se justifica por el amplio rango de condiciones en las que puede aplicarse el campo magnético, dependiendo de que sea estacionario o variable, de la intensidad del mismo, del tiempo de exposición o de la especie vegetal tratada (Maqueda, 2005). Los campos magnéticos estacionarios se generan mediante un imán (Figura 1a) o mediante cargas que se mueven como un flujo constante. Por otro lado, los campos magnéticos alternos o también llamados variables, invierten su sentido con una frecuencia regular y se producen por medio de dispositivos, por ejemplo, bobinas (Figura 1b) que usan corriente alterna.

El presente trabajo contempla la evolución histórica y los fundamentos básicos del magnetismo y del electromagnetismo, y una revisión bibliográfica sobre la aplicación de campos magnéticos en la agricultura.

\section{Historia del magnetismo}

Primeras civilizaciones. Se han de considerar como punto de partida dos fenómenos aislados que legaron las primeras civilizaciones que poblaron el planeta, despertando el interés por los efectos del magnetismo y el electromagnetismo: la atracción de los cuerpos ligeros por el ámbar frotado y la atracción del hierro por un mineral llamado piedra imán, conocido desde tiempos remotos en Magnesia (Asia Menor).

Civilización egipcia. El papiro de Ebers, que data del año 3600 a.C., relata cómo los egipcios utilizaban la magnetita en preparaciones médicas, sobre todo para heridas ocasionadas en la cabeza y también como amuleto. El interés de los egipcios por los animales de su entorno provocó que se interesaran por los fenómenos eléctricos asociados al pez gato eléctrico y a la anguila eléctrica. Este hecho se refleja en textos de 2750 a.C., que no solo describen estas especies como "truenos del Nilo" sino que los consideran protectores de los demás animales acuáticos. 


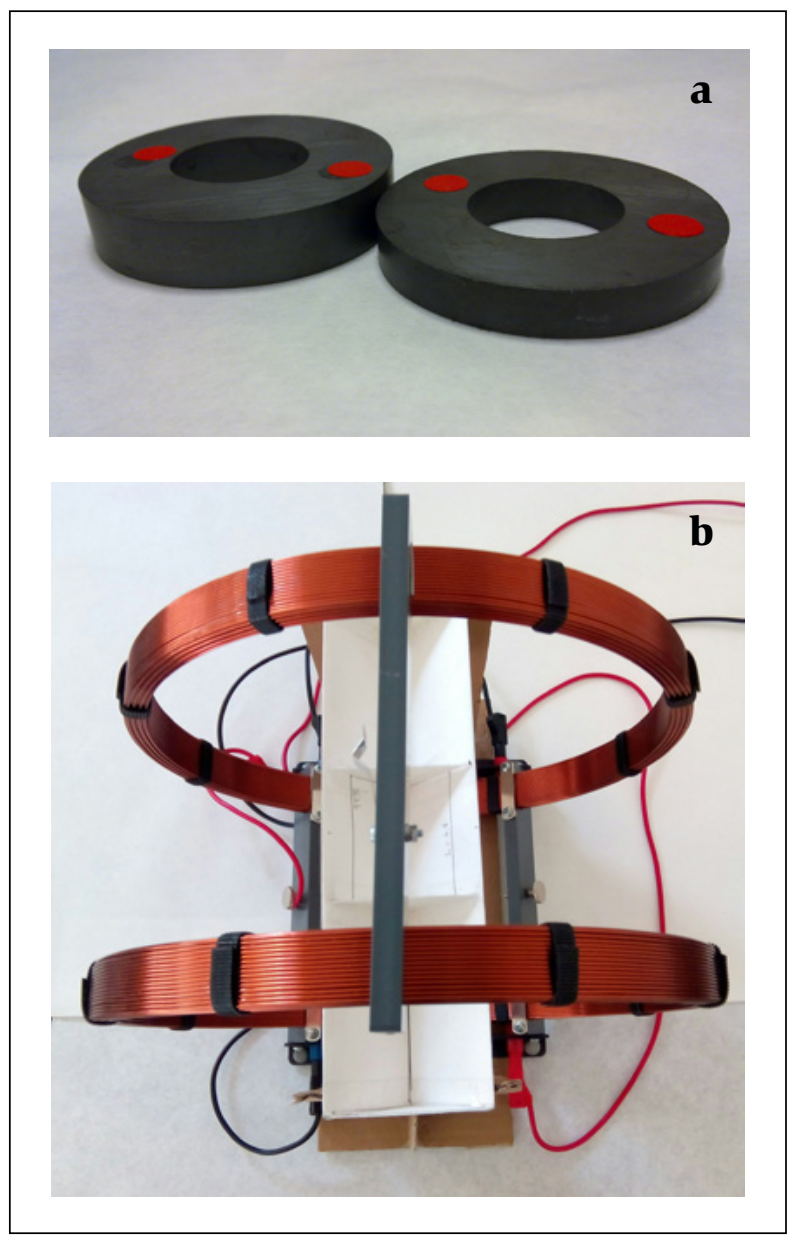

Figura 1 a. Los imanes generan campos magnéticos estacionarios. Imán de 250 mT (izquierda) e imán de 125 mT (derecha). b. Las bobinas generan campos magnéticos alternos. Bobina de Helmholtz. Fuente: Álvarez, J.

Civilización china. La literatura china refleja el descubrimiento del magnetismo en un escrito del siglo IV a.C. llamado , en el que se dice que "el imán hace venir al hierro o se atrae a sí mismo”. El general Haung Ti fue el primero en emplear la piedra imán como brújula en el año 376 a.C., aunque la primera referencia del uso de la brújula por parte de los chinos data del año 83 de nuestra era (Arnáldez y Beaujeu, 1973).

Civilización griega. Se calcula que los antiguos griegos sabían, aproximadamente desde el año 800 a.C., que la magnetita $\left(\mathrm{Fe}_{3} \mathrm{O}_{4}\right)$ atrae trozos de hierro. Se atribuye a Tales de Mileto (640-546 a.C.) haber sido el primero en llamar la atención sobre la electricidad y el magnetismo. Realizó la experiencia de frotar el ámbar con una pieza de lana o de piel y comprobó después que, al aproximarla a un objeto ligero, como una pluma, esta se desplaza hasta quedar adherida a él. Sus manuscritos no perduraron, pero Aristóteles (384-322 a.C.), razonando acerca de las propiedades del ámbar y el imán, y basándose en la lectura de los manuscritos de Tales de Mileto, afirmó que él atribuyó vida a lo inanimado, que "la piedra imán tiene alma porque atrae al hierro" y también que "todas las cosas están llenas de los dioses” (Lozano, 1995). Pitágoras de Samos (560-480 a.C.) describió la pirita magnética (Díaz-González, 1950), y más tarde Anaxágoras (499428 a.C.) la magnetita; Hipócrates (460-370 a.C.) usó la pirita magnética en medicina; Platón (428-348 a.C.) la llama piedra Magnesia, de donde procede el término de magnético, en referencia a la ciudad de la región histórica de Lidia, con gran cantidad de minas; Teofastro (371-287 a.C.) realizó en el 310 a.C. un estudio de los materiales que eran capaces de producir fenómenos eléctricos y escribió el primer tratado sobre la electricidad. Por último, cabría mencionar a Aristóteles (384-322 a.C.), que registró la imantación del hierro dulce bajo la acción de los imanes naturales.

Civilización romana. También los romanos cuentan sobre fenómenos magnéticos que no son atribuidos a otra cosa que al poder del magnetismo. El naturalista romano Plinio el Viejo lo atribuye a un pastor llamado Magnes, que se asombró de que la piedra imán atrajera los clavos de hierro de sus zapatos; en cambio, el poeta romano Lucrecio dice que el vocablo se deriva de Magnesia, nombre del viejo país donde se encontró la primera piedra imán (Lozano, 1995).

Época medieval. Durante siglos no se añadió nada nuevo al conocimiento de la electricidad y el magnetismo hasta que a finales del siglo XII llegó a occidente la brújula. En el siglo XIII, Pierre Pelerín de Maricourt, en su tratado "Epístola de Magnete" (1269), presenta por primera vez la aplicación de técnicas experimentales para la interpretación del fenómeno magnético. En la epístola describió la existencia de dos polos magnéticos en la piedra imán y sus interacciones, así como la propiedad de que, al partir un imán, aparecen dos imanes, cada uno de ellos con sus dos polos (Papp, 1961). También afirmó que la orientación de la aguja de una brújula se podía explicar con la existencia de yacimientos magnéticos en el Polo Norte (Arnáldez y Beaujeu, 1973).

Edad moderna. En los siglos siguientes, los principales descubrimientos sobre magnetismo fueron debidos a marinos y navegantes que utilizaban la brújula: Cristóbal Colón descubrió en 1492 la declinación magnética; Alonso de Santa Cruz fue el primero en 
idear la cartografía magnética en 1533; Robert Norman, un constructor de instrumentos para barcos, publicó hacia 1581 sus descubrimientos sobre la inclinación magnética y las variaciones locales en el libro "The New Attractive”; William Borough, en 1585, dio la definición de meridiano magnético (Lozano, 1995).

\section{El electromagnetismo}

El año 1820 resultó crucial en la historia de la ciencia del electromagnetismo. En 1813, Hans Christian Oersted (1777-1851) ya intuyó la existencia de fenómenos electromagnéticos. La descubrió en 1819, cuando observó cómo la aguja de una brújula colocada accidentalmente cerca de la corriente eléctrica se desviaba, constituyendo esta la primera evidencia que relacionaba la electricidad con el magnetismo.

Por cada punto de la Tierra pasan dos meridianos: el geográfico y el magnético. Ambos forman un cierto ángulo llamado declinación magnética, característico del lugar. La aguja magnética, al orientarse, queda en una posición que forma un cierto ángulo con el plano horizontal llamado de inclinación magnética. Jean Baptiste Biot (1779-1862) y Félix Savart (1791-1841) describieron, tan solo un mes después de los hallazgos de Oersted, los resultados de sus medidas del momento de fuerza que actúa sobre un imán próximo a un conductor largo por el que circula una corriente. También, en 1820, André-Marie Ampère (1775-1836) publicó sus primeras observaciones sobre las acciones magnéticas de las corrientes. En particular, demostró que dos corrientes eléctricas se ejercen fuerza entre sí, de atracción en el caso de los alambres paralelos que transportan corriente en el mismo sentido, o de repulsión si los sentidos de las dos corrientes son contrarios. Basándose en sus experiencias, Ampère formuló la hipótesis de que los imanes deben sus propiedades magnéticas a corrientes eléctricas microscópicas: el campo magnético es algo invariablemente unido a la corriente eléctrica (Bru, 1975).

William Sturgeon (1783-1850) inventó en 1825 el primer electroimán: imán en el que el campo magnético se produce mediante el flujo de una corriente eléctrica y desaparece en cuanto cesa dicha corriente. Michael Faraday (1791-1867), pionero de la física moderna y “padre de la electrotecnia”, elaboró una teoría completa sobre la electricidad que incluía el avance de la teoría electromagnética de la luz. En 1821, Faraday inventó un aparato para producir lo que llamaría . En realidad 146 se trataba de un motor electromagnético en el que la energía eléctrica podía convertirse en mecánica a través del magnetismo. En 1831 descubrió el fenómeno de la inducción magnética y la electrodinámica, con base en los cuales inventó el generador eléctrico y redactó las leyes de la inducción magnética. Fue el primero en descubrir la existencia de las líneas de fuerza al colocar limaduras de hierro en las proximidades de los polos de un imán y ver cómo se disponían a lo largo de las líneas imaginarias que unían los dos polos. En 1846 anunció que el magnetismo era una propiedad de la materia y clasificó los materiales en ferromagnéticos, diamagnéticos y paramagnéticos (Gamow, 2001). Con ayuda de su famosa jaula descubrió experimentalmente el principio de las pantallas eléctricas, ya demostrado teóricamente por Green. También, 50 años después de Cavendish, midió los poderes de inducción específicos, constantes dieléctricas, de diversos cuerpos aisladores (Abeles y Allard, 1973). El faradio, unidad del Sistema Internacional para la capacidad eléctrica, se denominó así en su honor.

Heinrich Friedrich Emil Lenz (1804-1865) enunció en 1833 la ley que explica el sentido de las corrientes inducidas. Joseph Henry (1799-1878) perfeccionó el electroimán y descubrió los cambios de polaridad al variar la dirección del flujo. Trabajó mucho en autoinducción, por lo cual la unidad de medida del Sistema Internacional, , fue nombrada así en su honor (Wood, 1991). En el año 1873, James Clerk Maxwell (1831-1879) dio una formulación matemática cuantitativa a las ideas de Faraday, relativas a la naturaleza y las leyes del campo magnético. De las ecuaciones de Maxwell se desprendió la existencia de ondas electromagnéticas que transportan energía. La existencia de estas ondas fue demostrada experimentalmente en 1888 por el físico alemán Henrich Hertz y condujo al desarrollo de la técnica de la radiocomunicación (Gamow, 2001).

Desde los trabajos de Oersted se sabe que una corriente eléctrica induce un campo magnético. Desde los trabajos de Faraday se sabe que, si un campo magnético cambia con el tiempo, se induce un campo eléctrico. De la hipótesis lanzada por Maxwell sobre la existencia de la corriente de desplazamiento se desprende que, si un campo eléctrico varía con el tiempo, se induce un campo magnético. Por tanto, si en una región del espacio existe un campo eléctrico que varíe con el tiempo, tiene que existir simultáneamente el magnético; los dos campos deben existir al mismo tiempo, es decir, debe existir el campo electromagnético. No puede existir un campo variable en el tiempo sin la existencia del otro. Sin embargo, en el caso estacionario (sin variación en el tiempo) sí es posible la existencia de uno solo de los 
campos. Por ejemplo, el campo magnético producido por un imán es constante en el tiempo y no lleva asociado un campo eléctrico. Por consiguiente, los campos eléctricos y magnéticos se propagan en el espacio y, como no pueden existir separadamente, es el campo electromagnético el que se propaga.

Maxwell encontró también que sus ecuaciones predecían el valor de la velocidad con que se propaga el campo electromagnético, que resultó ser igual a la velocidad de la luz. Para Maxwell esto no podía ser una casualidad y concluyó que "la luz es una perturbación electromagnética en forma de ondas que se propagan a través del campo electromagnético de acuerdo con las leyes del electromagnetismo".

A partir de la teoría de Maxwell se produjo un rápido progreso en el conocimiento del campo magnético y sus relaciones con la materia. Pierre Curie (18591906) estableció el comportamiento magnético de la materia con las variaciones de temperatura. Con la aparición de la Mecánica Cuántica surgió una nueva concepción del universo, aumentando rápidamente el conocimiento íntimo de la materia y el magnetismo. Langevin (1872-1946) formuló las leyes del magnetismo creado por la materia. Weiss (1865-1940) desarrolló las ideas de Langevin, estableciendo la existencia de dominios magnéticos y enunció la teoría del magnetón. Goudsmit (1902-1978) y Uhlenbeck (1900-1988) asignaron momento magnético propio al electrón, conocido como espín. Brilloulin (1889-1988), Van Vleck (1889-1980) y Heisenberg (1901-1976) desarrollaron la teoría cuántica del diamagnetismo, paramagnetismo y ferromagnetismo. En el momento actual, el magnetismo está estrechamente ligado a la estructura íntima de la materia.

William Gilbert de Colchester (1544-1603), médico de la Reina Isabel I de Inglaterra, recopiló todos los conocimientos que sobre el magnetismo existían en su época y los enriqueció con más de 50 experimentos propios. Con toda esta información, en 1600 publicó en Londres un tratado sobre magnetismo, , el primer estudio sistemático del magnetismo y la electricidad, debido al cual sus contemporáneos le dieron el nombre de "padre de la filosofía magnética" (Laín, 1973). Con Gilbert se inició el estudio de la electrostática y el magnetismo (Stern, 2001), y en su honor se nombró la unidad magnetomotriz en el sistema CGS: Gilbert.

Durante la segunda mitad del siglo XVIII, físicos de muchos países se dedicaron al estudio cuantitativo de las fuerzas eléctricas y magnéticas. Uno de los descubrimientos más importantes de esta época fue el realizado por el francés Charles Agustín de Coulomb (1736-1806), que ideó la llamada "balanza de torsión" para medir la fuerza de repulsión o atracción que ejercen entre sí dos cargas eléctricas. Coulomb estableció la relación de esta fuerza con la distancia mediante la ley que se lleva su nombre (Gamow, 2001).

\section{Fundamentos básicos del magnetismo}

El magnetismo es la parte de la física que estudia los fenómenos relativos a los imanes y al campo magnético creado por estos, así como el comportamiento de los diferentes materiales sometidos a la acción de dicho campo. Un imán consta de tres partes:

- Polos: Son los dos extremos del imán en los cuales las fuerzas de atracción son más intensas. Estos polos son el polo norte $(\mathrm{N})$ y el polo sur (S), también denominados polo positivo $\mathrm{y}$ negativo respectivamente. Polos del mismo tipo (combinaciones N-N y S-S) se repelen y los polos de distinto tipo (combinaciones N-S y S-N) se atraen.

- Eje magnético: Línea imaginaria que une los dos polos del imán.

- Línea neutral: Línea imaginaria que separa las dos zonas polarizadas.

Las corrientes eléctricas y, en general, las cargas en movimiento, se comportan como imanes o, lo que es lo mismo, producen campos magnéticos. Aunque las cargas eléctricas y los polos magnéticos de un imán son semejantes en muchos aspectos, hay una diferencia importante: los polos magnéticos siempre se presentan por parejas. Si se rompe un imán por la mitad, vuelven a aparecer los polos $\mathrm{N}$ y $\mathrm{S}$ en cada una de las mitades. La mayoría de los metales (hierro, acero...) son atraídos por los imanes; sin embargo, en algunos, como el oro o la plata, no tiene lugar este suceso. En el caso de la Tierra se pueden observar los polos magnéticos en oposición a los polos geográficos, tal como se refleja en la figura 2 .

Se considera por convenio que las líneas de campo salen del polo magnético norte y entran en el polo magnético sur, pero carecen de principio y fin, ya que no existen polos magnéticos aislados y, por lo tanto, las líneas continúan por el interior de la Tierra. El polo sur magnético se encuentra a 1800 kilómetros del polo norte geográfico; esta diferencia, medida en grados, se denomina declinación magnética (Tipler, 2008). 


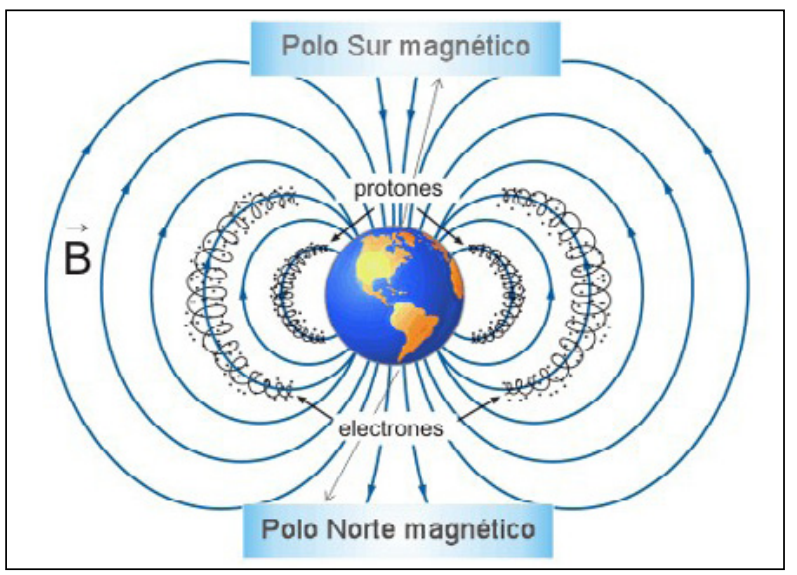

Figura 2. Líneas de campo magnético de la Tierra. Las partículas cargadas (protones y electrones) que provienen de las radiaciones solares se quedan atrapadas en las líneas de campo formando los cinturones de Van Allen. Fuente: Tipler y Mosca (2008).

\section{Carga eléctrica y campo magnético.}

La carga eléctrica es una propiedad fundamental de la materia y únicamente existe en múltiplos enteros positivos o negativos. La carga de un electrón es $\mathrm{e}=1,60 \cdot 10^{-19}$ culombios (Cheng, 1997). En un punto existe un campo magnético si una carga eléctrica móvil que pasa por dicho punto, además de sufrir una fuerza de carácter eléctrico, sufre otra fuerza. Los campos magnéticos pueden representarse por líneas de campo cuya dirección en cada punto puede representarse por un vector $\vec{B}$, que recibe el nombre de campo magnético. El número de líneas de fuerza que atraviesan una superficie se denomina "flujo magnético a través de la superficie” y se representa por $\emptyset$. Su expresión matemática corresponde a la ecuación (1):

$$
\emptyset=\int \vec{B} \cdot \overrightarrow{d S}=\int B \cdot \cos \varphi \cdot d S
$$

Siendo $\vec{B}$ el vector campo magnético y S la superficie; el valor de $\varphi$ en un punto de la superficie $S$ es el ángulo de los vectores $\vec{B}$ y y el elemento diferencial $\overrightarrow{d S}$ en dicho punto.

En el caso de flujo uniforme y normal a la superficie (2) se obtiene el producto escalar del campo B y la superficie S: $\quad \emptyset=B \cdot S$

\section{Fuerza ejercida por un campo magnético sobre una carga puntual}

Si en una región del espacio en la que existe campo magnético $\vec{B}$ se introduce una carga q que posee una velocidad $\vec{v}$ sufre una fuerza $\vec{F}$ que es proporcional a $\mathrm{q}$ y a $\vec{v}$ y al seno del ángulo $\alpha$ que forman $\vec{B}$ y $\vec{v}$. Por tanto,

$$
\vec{F}=\mathrm{q} \vec{v} \times \vec{B}
$$

La existencia de un campo magnético $\vec{B}$ en un punto del espacio puede demostrarse con una brújula. Si existe un campo magnético, la aguja se alineará en la dirección de este campo $\vec{B}$. La unidad del Sistema Internacional del campo magnético es el tesla $(\mathrm{T})$. Una carga de un culombio que se mueve con una velocidad de un metro por segundo perpendicular a un campo magnético de un tesla, experimenta una fuerza de un newton: $1 \mathrm{~T}$ $=1 \mathrm{~N} / \mathrm{A} \cdot \mathrm{m}$.

El campo magnético terrestre tiene un valor de aproximadamente $4 \cdot 10^{-4} \mathrm{~T}$ en la superficie de la Tierra. Los campos magnéticos cercanos a imanes industriales de gran tamaño son de $2 \mathrm{~T}$. La magnitud de estas cifras implica que sea de gran utilidad manejar una unidad más pequeña que el tesla, como el gauss $(G)$ siendo la equivalencia entre ambas: $1 \mathrm{~T}=10^{4} \mathrm{G}$ del sistema CGS.

En general, los materiales se pueden clasificar de acuerdo con su comportamiento magnético en diamagnéticos, paramagnéticos, ferromagnéticos, antiferromagnéticos, ferromagnéticos y superparamagnéticos. En los materiales diamagnéticos los efectos magnéticos son débiles. Por consiguiente, si un material diamagnético se coloca cerca de cualquier polo de un imán fuerte de barra, será repelido: un efecto descubierto por Michael Faraday en 1846. El material de Faraday era una porción de bismuto, una sustancia que presenta el diamagnetismo más fuerte que la mayoría de los materiales.

Los efectos magnéticos pueden ser significantes de modo que estas sustancias se denominan paramagnéticas. Cuando una sustancia paramagnética se coloca cerca del polo de una barra de imán, se atrae hacia el imán. En varios materiales, especialmente en el hierro, níquel y cobalto, ocurre un fenómeno especial que facilita enormemente el proceso de alineación. En estas sustancias denominadas ferromagnéticas, y 
en los materiales antiferromagnéticos, los momentos magnéticos de los átomos adyacentes se alinean en direcciones opuestas de manera que el momento magnético neto de un material es cero, aun en la presencia de un campo aplicado. A pesar de los efectos magnéticos más débiles, algunos de estos materiales ferromagnéticos, conocidos como ferritas, tienen una baja conductividad eléctrica que los hace útiles en los núcleos de inductores y transformadores, ya que las corrientes parásitas son menores y las pérdidas óhmicas, en forma de calor, se reducen. Un material superparamagnético consta de partículas ferromagnéticas suspendidas en una malla o matriz dieléctrica. Cada partícula puede contener muchos dominios magnéticos; con las partículas suspendidas en una cinta plástica delgada es posible cambiar el estado de magnetización abruptamente en una distancia muy pequeña de la cinta, de manera que puede almacenar grandes cantidades de información en forma magnética en longitudes convenientes. Tales cintas son muy usadas en audio, vídeo y sistemas de grabación de información.

\section{BIOELECTROMAGNETISMO}

Sobre la Tierra se pueden considerar campos magnéticos y eléctricos naturales (a los que permanentemente están sometidos los seres que viven sobre ella), y otros campos artificiales generados por el hombre. El campo eléctrico natural es el que denominamos campo eléctrico terrestre. Los campos electromagnéticos artificiales generados por el ser humano pueden ser de carácter magnético, eléctrico o de ondas electromagnéticas. Proceden de las líneas que transportan la energía eléctrica desde los centros de producción a los de consumo, de las instalaciones industriales y domésticas, de los sistemas de comunicaciones: radio, televisión, teléfonos móviles o fijos. Como estos medios generadores de campos electromagnéticos están creciendo con gran rapidez, la contaminación electromagnética asociada también está creciendo, al mismo ritmo que la preocupación de la población terrestre.

El bioelectromagnetismo es el estudio de los efectos de los campos electromagnéticos sobre los sistemas biológicos y sus interacciones con los campos naturales y artificiales. Bajo determinadas condiciones de laboratorio, han aparecido ciertos efectos biológicos asociados a estos campos que dependen de muchos factores: intensidad de los campos, tiempo de exposición y tipo de célula.

\section{Efectos del magnetismo natural en las especies vegetales}

Numerosos estudios han demostrado que los organismos se ven influenciados por el campo magnético de la Tierra, que oscila entre los 0,4 - 0,6 Gauss (Álvarez, 2011). Las fluctuaciones naturales de los campos magnéticos poseen un amplio espectro de efectos biológicos: pueden influir en la velocidad de reacciones bioquímicas, en las condiciones fisiológicas de los organismos, en su tasa de crecimiento e incluso su muerte (Novak y Valek, 1965; Es'kov et al., 2005). De hecho, para dichos autores el crecimiento está relacionado con la susceptibilidad magnética que presentan las semillas al campo magnético natural. Por otra parte, las fluctuaciones naturales del campo magnético han llevado a numerosos científicos a intentar simular esas condiciones en laboratorio y poder observar los resultados sobre determinadas especies vegetales. Es'kov y Radionov (2010) llevaron a cabo investigaciones con semillas de guisante $y$ trigo de invierno; se simulaban anomalías de campo magnético terrestre: el campo magnético terrestre circundante a las semillas era fortalecido o debilitado con un imán permanente. Para fortalecer este campo, las semillas se colocaron entre polos distintos de un imán y la localización del imán era coincidente con el vector del campo magnético de la Tierra. Para debilitar la influencia del campo magnético terrestre, las semillas se dispusieron entre polos iguales de un imán, se incluía un control.

La máxima longitud de plántulas y raíces se observó en semillas que germinaron en campos magnéticos fortalecidos. En el caso del guisante, las raíces y las plántulas llegaron a tener longitudes de un $10 \%$ y un 39 $\%$ superiores al control, respectivamente. Las radículas solían mostrar magnetotropismo, como se aprecia al comprobar que estas radículas, que tienen la propiedad de tener un crecimiento inicial muy fuerte, se orientaron a lo largo del eje magnético de la Tierra; las adaptaciones de los organismos a los campos magnéticos están relacionadas con la presencia de cobalto, hierro y otros materiales (Kirschvink et al., 1985), pudiendo ser la causa de la susceptibilidad a los campos magnéticos que presentan algunas especies de plantas. Dayal y Singh (1986) observaron que algunas variedades de tomate que habían sido sometidas a campos magnéticos de $125 \mathrm{mT}$, durante diversos periodos de tiempo aumentaron su longitud, especialmente si el tratamiento se prolongaba durante 15 minutos. También observaron que maduraron más rápido. 
Los efectos de los campos magnéticos sobre la germinación de semillas dependen de su orientación con respecto al vector del campo magnético terrestre (Pittman, 1963; Gorya, 1969; Travkin, 1969). De hecho, el rendimiento de las plantas varía con ella (Vetrov et al., 1989). Al colgar semillas de un hilo orientado en la dirección del vector del campo magnético de la Tierra, las líneas de campo atraviesan las semillas perpendicularmente, y por tanto el flujo de campo magnético al que se ven expuestas es el máximo posible (Es'kov y Darkov, 2003). El efecto biológico provocado por el campo magnético terrestre sobre las semillas depende también de la influencia de otros factores, entre los cuales se encuentran la humedad que presenten y la luz incidente (Jristova, 1986). En esta línea se destaca el trabajo de Matía et al. (2009) del Centro de Investigaciones Biológicas (CSIC) de Madrid, que centraron su estudio en los mecanismos moleculares de fenómenos biofísicos que tienen lugar en semillas expuestas a un entorno microgravitatorio. Para ello, enviaron al espacio semillas de Arabidopsis thaliana para estudiar su germinación en la órbita terrestre y su crecimiento: las plántulas crecieron durante 4 días y se fijaron en para-formaldehido; el experimento se repitió en la superficie terrestre en una máquina de posicionamiento al azar (un simulador de microgravedad efectivo). El crecimiento de las plántulas que habían sido expuestas a un entorno microgravitatorio fue significativamente superior que el crecimiento del control terrestre sometido a la gravedad; el crecimiento celular se incrementó mediante la sobreproducción de ribosomas, determinada por los parámetros morfológicos del nucléolo y por los niveles de la proteína nucleolar "nucleolin".

Como se ha indicado, se conoce la existencia de muchos factores que pueden intervenir en los resultados que se obtienen tras exponer a las plantas a diferentes campos magnéticos. Muchos de los efectos de estos campos han sido publicados, pero cabe preguntarse por las causas. Está demostrado que las plantas perciben los campos magnéticos, pero poco se sabe acerca de la naturaleza a nivel molecular y del grado de implicación de los diferentes órganos de la planta: ¿qué órganos son?, ¿qué naturaleza molecular y funcional tienen los receptores del campo?, ¿cómo se activan estos receptores?, ¿qué señales emiten para producir los efectos anteriormente descritos? Las investigaciones de ingenieros, físicos y biólogos en este campo se encaminan a dar respuestas a estas preguntas, intentando conocer los mecanismos con los que las plantas perciben estos campos y cómo 150 responden a ellos.
Se describen a continuación algunos tipos de procesos físicos o modelos que hipotéticamente tienen lugar en los mecanismos de interacción de los campos magnéticos con los sistemas biológicos de los seres vivos:

- Modelos de oscilación clásico y cuántico.

- Modelo de resonancia del ciclotrón.

- Interferencia de los estados cuánticos de los iones frontera y electrones.

- Efectos magnéticos de los momentos de torsión debidos a los campos magnéticos débiles.

- Estados metaestables biológicamente activos del agua líquida.

- Modelos de resonancia paramétricos.

Muchas de las investigaciones actuales consideran que los campos magnéticos cambian los niveles intracelulares de los iones $\mathrm{Ca}^{2+}$, iones que controlan un número importante de procesos en las plantas. Smith et al. (1993) relacionaron los efectos de los campos magnéticos variables sobre las plantas con los iones de $\mathrm{Ca}^{2+}$, llegando al resultado de que se estimulaba el crecimiento de las plantas cuando

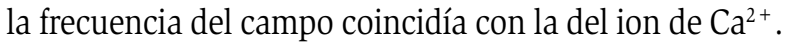
Sin embargo, la planta inhibía su crecimiento cuando la frecuencia del campo coincidía con la frecuencia del ion $\mathrm{de}^{+}$. Este crecimiento de los niveles está en consonancia con el modelo de resonancia paramétrica que había anunciado Lebenev en 1977, quien consideró que los campos eléctricos y magnéticos ejercen fuerzas oscilantes sobre los iones que se encuentran a ambos lados de las membranas plasmáticas de las células y que se pueden mover a través de ellas; cuando estas oscilaciones superan un cierto valor crítico, pueden afectar la función de la célula. Ruzic y Jerman (1998) estudiaron el efecto directo del campo magnético y el efecto indirecto a través del agua tratada magnéticamente mediante un campo magnético de extremada baja frecuencia (de $50 \mathrm{~Hz}$ y $105 \mu \mathrm{T}$ ), en el crecimiento de plántulas: las semillas se humedecieron con agua destilada y con disoluciones de $\mathrm{Ca}^{2+}$. El tratamiento magnético directo produjo un efecto significativamente inhibidor con disoluciones 0,5 $\mathrm{mM}$ de $\mathrm{Ca}^{2+}$ y el tratamiento indirecto produjo efecto significativamente inhibidor del crecimiento con 0,25 $\mathrm{mM}$ de $\mathrm{Ca}^{2+}$.

La estimulación de la germinación de la semilla en campos magnéticos estacionarios la explicaron Aladjadjiyan y Ylieva (2003), quienes asumieron la hipótesis de que algunos órganos de las células de las plantas (por ejemplo, las mitocondrias) poseen propiedades paramagnéticas. 


\section{Efectos de la aplicación de campos magnéticos estacionarios}

Los primeros estudios de aplicación de campos magnéticos a especies vegetales comenzaron con Savostin (1930), que observó un incremento en la tasa de crecimiento de las plántulas procedentes de semillas de trigo tratadas con campos magnéticos estacionarios (Carbonell et al., 2013). Pittman (1963) expuso semillas de cebada, lino, avena y centeno a un campo magnético estacionario de intensidad $254 \mathrm{mT}$ durante 48 horas; concluyó que la presencia del campo magnético y la orientación del eje longitudinal de las semillas respecto a las líneas de fuerza de dicho campo aumentaban la velocidad de germinación de las semillas. Campbell et al. (1964) sometieron semillas de cebada a un campo de $120 \mathrm{mT}$ y observaron diferencias de crecimiento de las plántulas obtenidas a partir de semillas tratadas respecto a las no tratadas; los tallos también mostraban una velocidad de crecimiento superior a las de control. Pittman (1965) realizó el estudio con maíz y judías, y observó que se produce un incremento en la velocidad de germinación y en el crecimiento, junto a una mayor pigmentación. Dycus et al. (1966) sugirieron que la orientación de los polos magnéticos podía actuar de diferente forma en la actividad de las enzimas de las plantas, así las semillas de cebada, maíz, pepino, veza y rábano aumentaban su crecimiento cuando sus raíces eran orientadas hacia el sur magnético.

Chao y Walker (1967) estudiaron la germinación de semillas de manzana, albaricoque y melocotón tratadas con un electroimán de $60 \mathrm{mT}$ de intensidad. Las semillas de manzana tratadas comenzaron a germinar en diez días: cinco días antes que las no tratadas. En albaricoque, las semillas tratadas empezaron a germinar pasados cuatro días de la siembra y completaron la germinación en diez días frente a los siete y veinte días respectivamente de las no tratadas; el porcentaje de semillas germinadas fue de $72-87 \%$ y $55 \%$ en el control. Por el contrario, no hubo diferencias entre semillas tratadas y no tratadas en melocotón.

Chausav (1967) fue uno de los investigadores que quiso conocer si el campo magnético terrestre tenía alguna influencia en la germinación de las semillas. Comprobó que cuando las semillas de trigo y maíz se orientaban en la dirección norte-sur del campo geomagnético, las plántulas mejoraban su crecimiento. Pittman y Ormrod (1971) sometieron semillas de cebada cervecera a un tratamiento magnético antes de su germinación y observaron que germinaban de ocho a doce horas antes que las semillas no tratadas.
Observaron también que las semillas tratadas tenían mayor nivel de azúcar que los controles. En un laboratorio, Pittman (1972) sometió tubérculos de patatas a un tratamiento de campo magnético y luego los sembró, observando que el tratamiento había influido en su cosecha. El tratamiento duró 240 horas y el campo magnético estacionario era de $115 \mathrm{mT}$. Obtuvo, como resultados más relevantes, un 14 \% más de producción de tubérculos comerciales por parte de las yemas u ojos de tubérculos tratados, así como un aumento del peso de la cosecha en un 38,5\%. Chauhan y Agrawall (1977), siguiendo los pasos de Chauvasv, orientaron semillas de trigo de la variedad Solanika en la dirección norte-sur del campo geomagnético y observaron que las semillas orientadas germinaban antes y las raíces laterales derechas crecieron más.

Lebedev et al. (1977) expusieron la cebada durante tres semanas a campos magnéticos estacionarios de $10 \mathrm{nT}$ y comprobaron un decrecimiento de hasta un $12 \%$ del peso fresco de los primeros brotes y de un $35 \%$ de las raíces, así como de $19 \%$ y $48 \%$ del peso seco respectivamente. Además, aprobaron un desarrollo más lento de las plantas ya que solo el $50 \%$ desarrollaron una tercera hoja, comparado con el 87 \% de las de control. Concluyó que los campos magnéticos débiles eran capaces de retrasar la formación del órgano y su desarrollo. Bhatnagar y Deb (1977) expusieron semillas de trigo a campos magnéticos de intensidades comprendidas entre 50 y $300 \mathrm{mT}$; la velocidad de germinación, longitud de raíz y tallo fueron significativamente mayores para las distintas intensidades de campo comparadas con el control: el máximo efecto se observó para $150 \mathrm{mT}$, seguido por 100 mT. Bogatina et al. (1978) observaron que las plántulas de trigo (Triticum aestivum L.) crecían más lentamente que las de control cuando las semillas se exponían a campos magnéticos estacionarios con un rango de $20 \mathrm{nT}$ a 0,1 mT durante tres a cinco días. Igualmente, un año más tarde, observaron que las plántulas de guisantes expuestas durante tiempos de entre tres y cinco días a campos de intensidad $40 \mu \mathrm{T}$ y $0,5 \mu \mathrm{T}$ crecían de forma más lenta, e incluso para una exposición de $2 \mu \mathrm{T}$, pero sin variar el peso seco en este último caso. Kursevich y Travkhin (1973) observaron una inhibición del crecimiento de las raíces de veza (Vicia villosa), mijo (Panicum miliare L.), cebada (Hordeum sativum L.) y guisantes cuando se exponían durante 48 y 72 horas a un campo magnético estacionario de 50 nT.

Gusta et al. (1978) trataron semillas de trigo, avena y cebada a cinco intensidades de campo magnético: 0, 25, 
50, 100 y $150 \mathrm{mT}$. Realizaron un seguimiento del proceso de germinación bajo dos condiciones de temperatura: $16^{\circ} \mathrm{C}$ y $21^{\circ} \mathrm{C}$; el ensayo tuvo una duración de 48 horas y realizaron conteos de las semillas germinadas cada 12 horas. Mientras que a $21^{\circ} \mathrm{C}$ no se observó efecto significativo sobre el proceso de germinación, tras 48 horas y a $16^{\circ} \mathrm{C}$ las semillas de trigo tratadas con $150 \mathrm{mT}$ mostraron mayor velocidad de germinación, comparado con el control. Esto sugiere que cuando las semillas se embebieron a baja temperatura, el efecto del campo magnético resultó más pronunciado. Shiyan (1978) comprobó que las semillas de los guisantes tenían un retraso en su germinación con campos estacionarios de $10 \mathrm{nT}$. Gubbels en 1982 expuso lotes de semillas de lino, maíz, girasol y guisantes a la acción de un campo magnético estacionario durante un tiempo muy corto, 10 segundos, y observó que un pequeño número de ellas dio lugar a plántulas con un crecimiento más temprano y vigoroso. Dayal y Singh (1986) observaron que algunas variedades de tomate que habían sido sometidas a campos magnéticos de $125 \mathrm{mT}$, aumentaban su longitud especialmente si el tratamiento se prolongaba durante quince minutos; también observaron que maduraban más rápido.

Kato et al. (1989) encontraron que las raíces secundarias de las semillas de maíz (Zea mays L cv Golden Cross Bantam 70) a las que se había inoculado Agrobacterium rizhogenes y expuestas, durante 12 horas en oscuridad a un campo magnético estacionario de $50 \mathrm{nT}$, tenían un crecimiento mayor que las de control. Vakharia et al. (1991) realizaron un tratamiento magnético de semillas de cacahuete previo a su siembra en macetas. Se utilizaron imanes permanentes de $10 \mathrm{mT}$ durante quince días y electroimanes de $24 \mathrm{~V}$ y $75 \mathrm{~A}$ durante 1 minuto. En las plantas procedentes de las semillas tratadas se observó, comparando con un control, un aumento en la longitud de las plantas, el número de brotes y el peso de hojillas por planta. La emergencia de las plántulas fue del $14 \%$ y $25 \%$ con imanes permanentes y electroimanes respectivamente. También aumentó el peso de materia fresca, materia seca, longitud y vigor de las plántulas. La influencia de un electroimán fue mayor que la de un imán permanente. También realizaron un estudio con semillas de tabaco con exposición a imanes de 50 y $100 \mathrm{mT}$ durante 30 y 60 minutos. Al comparar con un control, observaron un incremento en el contenido de clorofila del $16 \%$ y observaron también mayor longitud y anchura de las hojas, y mayor altura de la planta.

Como conclusión, en este periodo de tiempo que abarca 152 desde la primera referencia citada correspondiente a 1930 hasta principios de los años noventa, la investigación científica giraba en líneas generales en torno a los mismos parámetros como son el porcentaje de semillas germinadas, la velocidad de germinación o el crecimiento de plántulas. Por otro lado, aunque existe una gran variedad de especies vegetales citadas, los cereales cobraron mayor importancia debido posiblemente a su interés agronómico. A partir de este momento, aunque es cierto que se siguió mayoritariamente esta línea, se aprecian cambios sobre todo en los parámetros estudiados, introduciendo otros a nivel celular.

Pietruszewski (1993), trabajando con campos magnéticos de pequeña intensidad (comprendidos entre 10 y $30 \mathrm{mT}$ ), estudió el efecto en las propiedades biofísicas en cosechas de trigo; encontró un efecto positivo dependiendo del tiempo de exposición y del año de cultivo dado que el tratamiento magnético no solo incrementó la producción sino también el porcentaje de albúmina, gluten y almidón. Azanza y del Moral (1994) consideran este ion como modulador implicado en la interacción del campo magnético con la membrana plasmática. Namba et al. (1995) utilizaron campos magnéticos alternos que variaban de 1 a $1000 \mathrm{~Hz}$, con una intensidad de 4 - 5 gauss, para estudiar la germinación y el crecimiento de plantas de Komatsuna; los resultados mostraron máxima velocidad de germinación (20 \% superior al control) para frecuencia de $10 \mathrm{~Hz}$ y 5 gauss, lo que a la vez produjo mayor crecimiento de las plantas, evaluado por el área foliar. Algunos autores implican al ion $\mathrm{Ca}^{+2}$ y otros iones con la acción del campo magnético variable; Phirke et al. (1996 a,b) estudiaron el efecto de la intensidad del campo magnético y del tiempo de exposición en la producción de granos de soja, algodón y trigo. Se utilizó un rango de intensidades de campo magnético de 72-128 mT y tiempos de exposición comprendidos entre 13 y 27 minutos. Las dosis óptimas que permitieron obtener las máximas cosechas respecto al control fueron, para soja y algodón, de $100 \mathrm{mT}$ y 27 minutos, y para trigo de $100 \mathrm{mT}$ y 13 minutos, con aumentos en la producción de $46,14 \%$, 31,98 \% y 35,01 \% respectivamente. Singh et al. (1998) obtuvieron un incremento en la longitud del tallo y el número de brotes en las plántulas de mostaza (Brassica juncea L.), cuando las semillas se someten a un tratamiento de $30 \mathrm{mT}$ durante 6 horas. De Souza et al. (1999) realizaron un pretratamiento de semillas de tomate con campo magnético estacionario de 80,100 y $170 \mathrm{mT}$, durante diferentes tiempos de exposición: 1, 3, 5, 10, 15, 20, 
y 25 minutos. El tratamiento magnético provocó un aumento significativo con respecto al control en el porcentaje de semillas germinadas a los cinco y siete días; en la medición de tallo y raíz, a los catorce días obtuvieron un incremento significativo. Picazo et al. (1999) observaron la inhibición del crecimiento de plantas de cardo y lenteja que fueron sometidas a tratamiento magnético de $50 \mathrm{~Hz}$ y $15 \mu \mathrm{T}$ durante las primeras semanas de su desarrollo.

Carbonell et al. (2000) investigaron los efectos decampos magnéticos de 125 y $250 \mathrm{mT}$ sobre la germinación de semillas de arroz. Con el tratamiento crónico de $125 \mathrm{mT}$ se incrementó en un $18 \%$ el porcentaje de germinación. Con una exposición a $250 \mathrm{mT}$ durante 20 minutos el incremento fue del $12 \%$. Belyavskaya (2004) expuso semillas de guisantes (Pisum sativum L.) durante 3 días a un campo magnético variable de baja frecuencia y de intensidades entre 0,5 y 2 nT; observó que las raíces de las células del meristemo expuestas al campo experimentaban algunos cambios estructurales tales como la acumulación de cuerpos lipídicos y que las mitocondrias fueron los órganos más sensibles al campo magnético.

Novitsky et al. (2001) comprobaron que campos estacionarios de $0,5 \mathrm{mT}$ estimulaban de forma apreciable el crecimiento de las plántulas de rábano. Harichand et al. (2002) observaron que el tratamiento con $10 \mathrm{mT}$ durante cuarenta horas hacía incrementar la altura de la plántula, el peso de la semilla y el rendimiento en el cultivo de trigo. Ruzic y Jerman (2002) comprobaron que campos electromagnéticos de 100 nT no afectaban al crecimiento del mastuerzo (Lepidium sativum L.) después del estrés causado por el calor; sin embargo, disminuía el efecto inhibidor si el tratamiento era anterior.

Panagopulos et al. (2002) desarrollaron un modelo biofísico para explicar la acción biológica de los campos eléctricos y magnéticos variables de baja frecuencia. Su teoría se basa en la hipótesis de que los campos externos ejercen fuerzas oscilantes sobre los iones libres que se encuentran a ambos lados de todas las membranas plasmáticas, y que se pueden mover a través de ellas por medio de las membranas de proteínas. Estas fuerzas externas obligan a estos iones a oscilar de manera que, cuando la amplitud de estas oscilaciones sobrepasa un determinado valor crítico, los iones oscilantes pueden dar una falsa alarma a canales de cierre que son eléctrica o mecánicamente sensibles, desordenando, de esta forma, el balance electromecánico de la membrana plasmática y, por consiguiente, toda la función de la célula. Martínez et al. (2003) observaron que las semillas de trigo sometidas a campos magnéticos estacionarios de 125 y $250 \mathrm{mT}$ mostraban un crecimiento más temprano en las plántulas que las semillas no tratadas magnéticamente. Aladjadjiyan e Ylieva (2003) estudiaron la influencia de los campos magnéticos estacionarios en los primeros estados de desarrollo de tabaco (Nicotiana Tabacum L.), con el fin de aplicarlo posteriormente a la agricultura práctica. Comprobaron que la germinación y la energía de germinación de las semillas aumentaban de forma lineal con el tiempo de exposición al campo magnético. De la misma forma, demostraron que el aumento en la germinación era mayor cuando la semilla había sido empapada de agua previamente.

Albertini et al. (2003) estudiaron "in vitro" los efectos de los campos magnéticos sobre el hongo Fusarium. Su objeto era estudiar si estos campos podían disminuir o anular los efectos dañinos de estos hongos en los cereales que son fuente de micotoxinas y que afectan a la salud de personas y animales. Comprobaron, entre otros efectos, la inhibición del crecimiento de las micelas, cambios bioquímicos y morfológicos, así como la influencia sobre los iones de $\mathrm{Ca}^{+2}$. Algunos de los cambios morfológicos eran similares a los obtenidos anteriormente mediante fungicidas.

Dini y Abbro (2004) hacen referencia a los innumerables efectos de los campos magnéticos sobre la estructura y las funciones de la célula: reorientación de los dominios diamagnéticos moleculares, transporte de iones de calcio $\left(\mathrm{Ca}^{+2}\right)$ a través de las membranas celulares, cambios en la forma de la célula, etc. Belyavskaya (2004) comprobó que las semillas de trigo, sometidas a $30 \mathrm{mT}$ durante quince minutos, presentaban una formación del número de raíces un $25 \%$ superior al control.

Flórez (2004) investigó los efectos que producen en la germinación y en las primeras etapas de desarrollo de las plantas, la aplicación de campos magnéticos estacionarios de $125 \mathrm{mT}$ y $250 \mathrm{mT}$ y diferentes periodos de exposición: 1, 10 y 20 minutos, una hora, 24 horas y exposición crónica. Las semillas tratadas fueron trigo, cebada, maíz, arroz, lentejas, alfalfa, girasol, tomate y cardo. En todas las especies seleccionadas, la velocidad de germinación aumentó con la exposición a un campo magnético estacionario de $125 \mathrm{mT}$ o $250 \mathrm{mT}$ de forma continua durante todo el proceso de germinación, y con la exposición durante 24 horas. Las plántulas que se 
desarrollaron bajo la presencia continuada de un campo magnético de 125 o $250 \mathrm{mT}$, o durante 24 horas, mostraron un crecimiento más rápido o más temprano que plántulas desarrolladas en las mismas condiciones ambientales sin ser sometidas a la presencia del campo magnético.

Maqueda (2005) investigó el efecto que se produce en la germinación y en las primeras etapas del crecimiento del guisante al exponerlo a campos magnéticos estacionarios, descrito por Flórez. Las semillas expuestas mostraron, para todos los tiempos, una velocidad de germinación superior a la de las semillas de los controles, y también mostraron un crecimiento significativamente más temprano. Alcázar (2005) investigó los efectos que produce, en la germinación de semillas de avena loca y cardo de Castilla, la aplicación de las mismas dosis magnéticas estacionarias; para ambas especies, los resultados obtenidos en cuanto al desarrollo de la plántula ofrecen siempre diferencias muy significativas frente al control. Los estudios desarrollados por Flórez et al. (2007) con maíz de la variedad Ramda también resultaron muy favorables a los tratamientos magnéticos descritos.

Torres et al. (2008) realizaron un pretratamiento magnético a semillas de arroz y tomate con dos niveles de intensidad de campo magnético estacionario (5 y 10 $\mathrm{mT}$ ) durante diferentes tiempos de exposición: 1, 10, 20, 60 minutos, 24 y 48 horas, resultando que el número de semillas germinadas era significativamente mayor que el control para ambos cultivos y se dio también un incremento de la biomasa en las plantas de tomate.

Vashisth y Nagarajan (2010) estudiaron los efectos del pretratamiento sobre las semillas de girasol. Los resultados indicaron que el incremento en la velocidad de germinación, la longitud de las plantas y su peso, al mes resultaron significativamente mayores a los del control en todos los tratamientos. Cakmak et al. (2010) estudiaron la aceleración de la germinación y las primeras etapas de crecimiento de semillas de trigo y judía bajo el efecto de distintos campos magnéticos estacionarios. Los porcentajes de germinación de las semillas tratadas fueron mayores que los de las semillas sin tratar (control) y las mejores tasas de germinación y crecimiento, en ambos casos, se dieron en campos magnéticos estacionarios de $7 \mathrm{mT}$.

Hajnorouzi et al. (2011) estudiaron el crecimiento y estrés oxidativo de plántulas de maíz mediante una combinación de campos electromagnéticos y 154 geomagnéticos. Este equipo sugiere que la combinación apropiada de estos campos promueve la germinación y el crecimiento del maíz por una disminución de la producción excesiva de especies reactivas al oxígeno. La conservación de la integridad de la membrana y la disminución del contenido en hierro de las plántulas tratadas bajo campo magnético, parecen sugerir que esta combinación promueve el crecimiento.

Álvarez (2011) investigó el efecto que se produce en la germinación y en las primeras etapas de crecimiento del cereal triticale al exponerlo, después de su siembra (tratamiento en húmedo), a campos magnéticos estacionarios de $125 \mathrm{mT}$ y $250 \mathrm{mT}$ durante diferentes periodos de exposición: 1,10 y 20 minutos, 1 hora, 24 horas y exposición crónica. Los resultados indicaron un aumento en la velocidad de germinación tras exposiciones durante 24 horas y de forma permanente. En las semillas de triticale expuestas antes de su siembra (pretratamiento o tratamiento en seco) se observó también un aumento en su velocidad de germinación. Shine et al. (2011) estudiaron el efecto de campos magnéticos estacionarios (usando campos desde 0 hasta $300 \mathrm{mT}$, de $50 \mathrm{mT}$ en $50 \mathrm{mT}$ ) en semillas de soja (Glycine max L. Mer. Var: JS-335) expuestas durante 30, 60 y 90 minutos. Las mejoras respecto al control fueron del 5 - $42 \%$ para la velocidad de germinación, del 4 - $73 \%$ para la longitud de la plántula, del 9 - $53 \%$ para el peso húmedo (5 - $16 \%$ en seco) y del 3 al 88 $\%$ en cuanto a vigor.

Carbonell et al. (2011) expusieron semillas de guisante (Pisum sativum L.) a campos magnéticos estacionarios de $125 \mathrm{mT}$ y $250 \mathrm{mT}$, y estudiaron los efectos en los estados iniciales de crecimiento. La longitud y el peso de las plántulas a las que se había aplicado dicho tratamiento magnético fueron superiores a los de control en todos los tiempos de evaluación. Los mejores resultados se obtuvieron para exposición continua. Flórez et al. (2012) estudiaron el efecto que tiene el tratamiento magnético en la germinación de semillas de Salvia officinalis L. y Calendula officinalis L. Los parámetros de germinación en cada tratamiento y pretratamiento resultaron más bajos que el control. Los mejores resultados se obtuvieron para la exposición crónica a campos de $125 \mathrm{mT}$.

Gutiérrez et al. (2014) determinaron el efecto de la exposición a campos magnéticos sobre los parámetros germinación, crecimiento y flora microbiana asociada a semillas y plántulas de Brachiaria humidicola, Panicum maximum y Zea mais (Poaceae). Los resultados 
mostraron un efecto positivo sobre la germinación, especialmente para Brachiaria humidicola, ayudando con creces a superar el periodo de latencia que presenta esta especie. Por otro lado, una prolongada exposición de 48 horas reflejó una pequeña reducción en la población de microorganismos asociados, en especial hongos, en las diferentes especies estudiadas.

En la década actual, continúa la tendencia iniciada a principios de los años 90, apareciendo cada vez más artículos en los que se exponen estudios que constituyen una mezcla de investigaciones clásicas basadas en efectos de campos magnéticos sobre parámetros de germinación y crecimiento, complementándose con el estudio de otros aspectos relacionados con procesos celulares o la fotosíntesis. Tomando como referencia este segundo carácter, destacan:

Radhakrishnan y Kumari (2012) han publicado que la aplicación de campos magnéticos pulsátiles durante 20 días sobre semillas de soja, aparte de incrementar la altura de las plántulas correspondientes y el peso en fresco y seco, aumenta el contenido en proteína y la actividad de las enzimas $\beta$-amilasa, fosfatasa ácida, polifenol oxidasa y catalasa. También aumenta la concentración de los elementos $\mathrm{Fe}, \mathrm{Cu}, \mathrm{Mn}, \mathrm{Zn}, \mathrm{Mg}, \mathrm{K}$ y Na. Sin embargo, la actividad de otras enzimas se ve reducida, como es el caso de la $\alpha$-amilasa, fosfatasa alcalina, proteasa y nitrato reductasa, así como la de Ca. Siguiendo esta línea, Bhardwaj et al. (2012) también han descubierto un aumento de las enzimas hidrolíticas, amilasa y proteasa en semillas de pepino para diferentes tiempos y tratamientos de 100 y $250 \mathrm{mT}$.

Hozayn et al. (2015) han observado un incremento significativo en la actividad mitótica de las células de plántulas de cebolla, con tan sólo 30 minutos de tratamiento con 0,03 T y 0,06 T. Por otro lado, también se presentaron más casos de aberración cromosómica $\mathrm{y}$ anormalidades en la mitosis.

Baghel et al. (2016) han descubierto que la aplicación de campos magnéticos estacionarios de $200 \mathrm{mT}$ durante tan solo una hora, consigue mitigar los efectos adversos de la salinidad en el medio de las plantas de soja o, lo que es lo mismo, evitar disminuciones en el rendimiento, crecimiento y otros parámetros fisiológicos. Además, la tasa fotosintética neta, la actividad de la enzima nitrato reductasa y de los pigmentos fotosintéticos, todas ellas relacionadas con el funcionamiento celular y la fotosíntesis, son mayores debido a estos campos.
En este periodo también encontramos nuevas revisiones bibliográficas que actualizan y complementan teorías y principios conocidos de hace tiempo, como es el caso de Maffei (2014), que se centra en la fuerte influencia del campo magnético natural de la tierra sobre el movimiento o comportamiento de seres vivos, como bacterias magnetotácticas, insectos, anfibios, peces y mamíferos. Por otro lado, el gran número de efectos positivos que se observan en las especies vegetales, bajo aplicaciones breves de campos magnéticos, nos indica la capacidad de estas especies para responder rápidamente a este tipo de estímulo, sobre todo a través de la alteración de su expresión génica y su fenotipo. Por su parte, Zúñiga et al. (2016a) hacen una revisión acerca del agua tratada magnéticamente y sus efectos a nivel molecular, relacionados con una mayor eficiencia en el riego y el uso del agua. También resalta que, a pesar del evidente efecto que tienen los campos magnéticos sobre el mayor rendimiento de germinación de semillas y crecimiento de plántulas, se carece de un procedimiento estandarizado del tratamiento sobre especies vegetales, lo que facilitaría su aplicación a gran escala. Además, medioambientalmente constituye una técnica mucho menos contaminante y agresiva que otras.

Un enfoque diferente resulta de las investigaciones de Zúñiga et al. (2016b), quienes han aplicado una estimulación electromagnética, gracias a un solenoide, sobre un bio-fertilizante que posibilitaría una mejora gradual en la población microbiana benéfica del suelo y en consecuencia en la producción vegetal.

\section{CONCLUSIÓN Y PERSPECTIVA DE FUTURO}

La corriente investigadora de aplicación de campos magnéticos sobre especies vegetales, que comenzó a principios del siglo XX y que perdura hasta nuestros días, ofrece como conclusión mayoritaria que los campos magnéticos estacionarios y alternos favorecen la germinación de semillas y el crecimiento de plantas de un gran número de especies. Más recientemente, los análisis en este campo se han dirigido hacia el estudio de los efectos de campos magnéticos, pero esta vez sobre parámetros o fenómenos fisiológicos a nivel celular, con resultados interesantes.

Llegados a este punto, y como perspectiva de futuro, sería necesario estandarizar unas condiciones de aplicación de los campos magnéticos, factor que 
ya un gran número de autores vienen reclamando. Asimismo, podría ser de gran valor establecer si es rentable la aplicación de campos magnéticos a gran escala para obtener un incremento en el rendimiento de los cultivos o un adelanto en las cosechas. El estudio económico debería desarrollarse en forma paralela a la realización de estudios de seguridad alimentaria para ver la posible influencia que puedan causar especies vegetales tratadas sobre la salud humana o animal.

\section{AGRADECIMIENTOS}

Nuestro agradecimiento a la Universidad Politécnica de Madrid por financiar el grupo de Investigación "Bioelectromagnetismo aplicado a la Ingeniería Agroforestal" que ha permitido realizar investigaciones mediante la aplicación de campos magnéticos estacionarios en distintas especies vegetales.

\section{BIBLIOGRAFÍA}

Abeles, F. y Allard, G. 1973. La Ciencia Contemporánea. El siglo XIX. Editorial Destino, Barcelona.

Aladjadjiyan, A. y Ylieva, T. 2003. Influence of stationary magnetic field on the early stages of development of tobacco seeds (Nicotina tabacum, L.). Journal of Central European Agriculture 4(2): 132-136.

Albertini, M.C., Accorsi, A., Citterio, B., Burattini, S., Piacentini, M.P., Uguccioni, F. y Piatti, E. 2003. Morphological and biochemical modifications induced by a static magnetic field on Fusarium culmorum. Biochimie 85(10): 963-70.

Alcázar, S. 2005. Efecto de campos magnéticos estacionarios de $125 \mathrm{mT}$ y $250 \mathrm{mT}$ en la germinación de semillas de avena loca y cardo de castilla. Trabajo Fin de Carrera, Escuela Técnica Superior de Ingenieros Agrónomos, Universidad Politécnica de Madrid, España.

Álvarez, J. 2011. Exposición de semillas de Triticale a campos magnéticos estacionarios de $125 \mathrm{mT}$ y $250 \mathrm{mT}$. Efectos en la velocidad de germinación y primeras etapas de desarrollo. Trabajo Fin de Carrera, Escuela Técnica Superior de Ingenieros Agrónomos, Universidad Politécnica de Madrid, España.

Arnáldez, R. y Beaujeu, J. 1973. La Ciencia Antigua y Medieval. Editorial Destino, Barcelona.

Azanza, M.J. y Del Moral, A. 1994. Cell membrane biochemistry and neurobiological approach to 156 biomagnetism. Progress in Neurobiology 44: 517-601.
Baghel, L., Kataria, S. y Guruprasad, K.N. 2016. Static magnetic field treatment of seeds improves carbon and nitrogen metabolism under salinity stress in soybean. Bioelectromagnetics 37(7): 455-70.

Bhardwaj, J., Anand, A. y Nagarajan, S. 2012. Biochemical and biophysical changes associated with magnetopriming in germinating cucumber seeds. Plant Physiology and Biochemistry 57: 67-73.

Belyavskaya, N.A. 2004. Biological effects due to weak magnetic field on plants. Original Research Article Advances in Space Research 34(7): 1566-1574.

Bhatnagar, D. y Dev, A.R. 1977. Some effect of pregermination exposure of wheat seeds to magnetic fields. Effect on some physiological process. Seed Research 5(2): 129-137.

Blakemore, R. 1975. Magnetotactic bacteria. Science 190: 377-379.

Bogatina, N.I., Verkin, B.I., Kordyum, V.A. 1978. Effect of permanent magnetic fields with different intensities on wheat growth rate. Doklady Akademii Nauk Ukrainskoj SSR Serija A, Russian B (4): 352-356.

Braun, E. 2003. Electromagnetismo de la ciencia y la tecnología. Fondo de cultura económica, México D.F.

Bru, L. 1975. Física. Librería Internacional de Romo S.L, Madrid.

Buck, J.A. y Hayt, W.H. 2006. Engineering Electromagnetics. McGraw-Hill, New York.

Cakmak, T., Dumlupinar, R. y Erdal, S. 2010. Acceleration of Germination and Early Growth of Wheat and Bean Seedlings Grown Under Various Magnetic Field and Osmotic Conditions. Bioelectromagnetics 31: 120-129.

Campbell, W.F., Mericle, L.W., Mericle, R.P., Montgomery, D.J. y Smith, A.E. 1964. Plant Growth responses, Biological effects of Magnetic Fields. Plenum Press, New York.

Carbonell, M.V., Martínez, E. y Amaya, J.M. 2000. Stimulation of germination in rice (Oryza sativa L.) by a static magnetic field. Electromagnetic Biology and Medicine 19(1): 115-120.

Carbonell, M.V., Flórez, M., Martínez, E., Maqueda, R. y Amaya, J.M. 2011. Study of stationary magnetic fields on 
initial growth of pea (Pisum sativum L.) seeds. Seed Science and Technoly 39: 673-679.

Carbonell, M.V., Martínez, E. y Flórez M. 2013.Tratamiento magnético como técnica estimulante de la germinación de semillas de Soja. Revista Ingeniería de los Recursos Naturales y del Ambiente - EIDENAR 12: 119- 127.

Chao, L. y Walker, D. 1967. Effects of magnetic field on the germination of apple, apricot and peach seeds. Horticultarae science 2(4): 152-153.

Chauhan, T.S. y Agrawal, A.S. 1977. Effect of magnetism on germination of Sonalika wheat. Acta Botanica (India) 5: 66-68.

Chausav, R.P. 1967. Effect of magnetic field and rotation of the Earth on seed germination and shoot growth. Fizologiya Rast 14: 540-543.

Cheng, D.K. 1997. Fundamentos de electromagnetismo para ingeniería. Addison-Wesley Iberoamericana, México D.F.

Dayal, S. y Singh, N. 1986. Effect of seed exposure to magnetic field on the height of tomato plants. Indian Journal of Agricultural Sciences 56 (6): 483-487.

De Souza, A., Porras, E. y Casate, R. 1999. Efecto del tratamiento magnético de las semillas de tomate sobre la germinación y el crecimiento de las plántulas. Investigación agraria, producción y protección vegetales 14(3): 437-444.

Díaz-González, J. 1950. Historia de la Medicina en la Antigüedad. Editorial Barna, Barcelona.

Dini, L. y Abbro, L. 2004. Bioeffects of moderate-intensity static magnetic fields on cell cultures. Micron 36: 195-217.

Dycus, A.M., Shultz, A. y Smith, P. 1966. Effect on early plant growth of nulled and directional magnetic field environment. $3^{\text {rd }}$ International Biomagnetic Symposium. Universidad de Illinois, Chicago.

Es'kov, E.K. y Darkov, V.A. 2003. Consequences of high intensity magnetic effects on the early growth Processes in plant seeds and the development of honeybees. Biology Bulletin 30(5): 617-622.

Es'kov, E.K., Darkov, A.V. y Shvetsov, G.A. 2005. Dependence of the magnetic susceptibility of biological objects on their physiological state and viability. Biofizika 50(2): 357-389.

Es'kov, E.K., Radionov, A. y Yu, A. 2010. Initial growth processes in seeds in magnetic fields, strengthened or weakened in relation to the geomagnetic field. Biology Bulletin 37(1): 49-55.

Flórez, M. 2004. Efecto de campos magnéticos estacionarios de $125 \mathrm{mT}$ y $250 \mathrm{mT}$ en la germinación de semillas y desarrollo de plántulas. Tesis de doctorado, Universidad Politécnica de Madrid, España.

Flórez, M., Carbonell, V. y Martínez, E. 2007. Exposure of maize seeds to stationary magnetic fields: effects on germination and early growth. Environmental and Experimental Botany 59(1): 68-75.

Flórez, M., Martínez, E. y Carbonell, M.V. 2012. Effect of magnetic field treatment on germination of medicinal plants Salvia officinalis $L$. and Calendula officinalis $L$. Polish Journal of Environmental Studies 21: 57-63.

Gamow, G. 2001. Biografía de la Física. Alianza Editorial, Madrid.

Gorya, V.S. 1969. The effect of seeds orientation in soil relative to geomagnetic pole on the growth and development of Maize. Brief results of work Moldavian Institute of Plant and Seed Breeding and Agrotechnology of Field Crops, Chisinau.

Gubbels, G.H. 1982. Seedling growth and yield response of flax, buckwheat, sunflower and field pie after pre seedling magnetic treatment. Canadian Journal of Plant Science 62: 61-64.

Gusta, L.V., Kirkland, K.J. y Austenson, H.M. 1978. Effects of brief magnetic exposure on cereal germination and seedling growth. Canadian Journal of Plant Science 58: 79-86.

Gutiérrez, A.M., Torres, C. y Díaz, J.E. 2014. Effect of magnetic fields in germination, growth, and microbial florishing in seedlings of Brachiaria humidicola, Panicum maximum, and Zea mays (Poaceae). Revista de Ciencias 18(1): 9-17.

Hajnorouzi, A., Vaezzadeha,M., Ghanatib, F., Jamnezhada, H. y Nahidianb, B. 2011. Growth promotion and a decrease of oxidative stress in maize seedlings by a combination of geomagnetic and weak electromagnetic fields. Journal of Plant Physiology 168: 1123-1128.

Harichand, K.S., Narula, V. y Raj, D. 2002. Effect of magnetic fields on germination, vigour and seed yield of wheat. Seed Research 30(2): 289-293. 
Hozayn, M. Amal, A.A. y Abdel-Rahman, H.M.H. 2015. Effect of magnetic field on germination, seedling growth and cytogenetic of onion (Allium cepa L.). African Journal of Agricultural Research 10(8): 849-857.

Jristova, M. 1986. Técnicas de Irradiación en la Agricultura y la Industria Alimenticia. Memorias escuela para los problemas actuales de las ciencias nucleares, La Habana.

Kato, R., Kamada, H. y Aashima, M. 1989. Effects of high and very low magnetic field on the growth of hairy roots of Daucus carota and Atropa beladonna. Plant Cell Physiology 30: 605-608.

Kirschvink, J.L., Jones, D.S. y McFadden, B.J. 1985. Magnetite Biomineralization and Magnetoreception in Organisms: A New Biomagnetism. Ed. Plenum Press, New York.

Kirschvink, J. y Walker, M. 2001. Magnetic-based magnetoreception. Current Opinion in Neurobiology 11: 462-467.

Kursevich, N.V. y Travkin, M.P. 1973. Effects of magnetic fields with different intensities on some enzymes activities in barely seedlings. En: Belgorod Teacher's Training College Publishing Co. Effects of Natural and Weak Artificial Magnetic Fields on Biological Objects. Training College Publishing Co, Belgorod.

Laín Entralgo, P. 1973. Historia Universal de la Medicina. Editorial Salvat. Barcelona. España.

Lebedev, S.I., Baranskiy, P.I., Litvinenko, L.G., Shiyan, L.T. 1977. Barley growth in superweak magnetic field. Electronic Treatment of Materials 3: 71-73.

Lozano, E. 1995. Historia de la electricidad y el magnetismo. Su aplicación en medicina. Tesis Doctoral, Universidad de Alcalá de Henares, Madrid, España.

Maffei, M.E. 2014. Magnetic field effects on plant growth, development, and evolution. Frontiers in Plant Science 5: 445.

Maqueda, M.R. 2005. Efecto de la exposición a campos magnéticos de $125 \mathrm{mT}$ y $250 \mathrm{mT}$ en la germinación y primeras etapas de crecimiento del guisante. Trabajo fin de carrera, Escuela Técnica Superior de Ingenieros Agrónomos, Universidad Politécnica de Madrid, España.

Matía, I., González-Camacho, F., Herranz, R., Kiss, J.Z., Gasset, G., J.W.A. van Loon, J., Marco, R. y Medina, F.J. microgravity conditions in spaceflight. Journal of Plant Physiology 167: 184-193.

Martínez, E., Carbonell, M.V. y Flórez, M. 2003. Magnetic biostimulation of initial growth stages of wheat (Triticum aestivum L.). Electromagnetic Biology and Medicine 21(1): 43-53.

Mouritsen, H. 2001. Navigation in birds and others animals. Image and Vision Computing 19(11): 713-731.

Namba, K., Sasao, A. y Shibusawa, S. 1995. Effect of magnetic field on germination and plant growth. Acta horticulturae 399: 143-147.

Novak, J. y Valeck, L. 1965. Attempt of Demonstrating the Effect of Weak Magnetic Field on Taraxacum officinale. Biologia Plantarum 7(6): 469.

Novitsky, G. V. A., Tserenova, O. A., Kocheshkova, T. K. y NovitskiiYu, I. 2001. The effect of weak permanent magnetic field on cotyledon emergence and neutral lipid content in 5-day-old radish seedlings. Plant under Environmental Stress. University of Russia, Moscú.

Panagopoulos, D.J., Karabarbounis, A. y Margaritis, L.H. 2002. Mechanism for action of electromagnetic fields on cells. Biochemical and Biophysical Research Communications 298: 95-102.

Papp, D. 1961. Historia de la Física. Editorial Espasa Calpe, Madrid.

Pérez, C. y Brady, L. 1998. Principles and Practice of Radiation Oncology. $3^{\mathrm{a}}$ ed. Editorial Lippincott-Raven, New York.

Phirke, P.S., Patil, M.N., Umbakar, S.P. y Dudhe, Y.H. 1996a. The application of magnetic treatment to seeds: methods and responses. Seed Science and Technology 24: $365-373$

Phirke, P.S., Kubde, A.B. y Umbakar, S.P. 1996b. The influence of field on plant growth. Seed Science and Technology 21: 621-626.

Picazo, M.L., Martínez, E., Carbonell, M.V., Raya, A., Amaya, M. y Bardasano, J.L. 1999. Inhibition in the growth of thistles (Cynara cardunculus, L.) and Lentils (Lens culinaris, L) due to chronic exposure to $50 \mathrm{~Hz}$ and $15 \mu \mathrm{T}$ electromagnetic fields. Electro- and Magnetobiology 18 (2): 147-156.

Pietruszewski, S. 1993. Effect of magnetic seed treatment on yields of wheat. Seed and Technology 21: 621-626. 
Pittman, U. 1963. Effects of Magnetism of Cereal Plants. Biomedical Science Instrum 1:117-123.

Pittman, U.J. 1965. Magnetism and growth III. Effect on germination and early growth of corn and beans. Canadian Journal of Plant Science 45: 549-555.

Pittman, U.J. y Omrod, D.P. 1971. Biomagnetic responses in germinating malting barley. Canadian Journal of Plant Science 51: 64-65.

Pittman, U.J. 1972. Biomagnetic responses in potatoes. Canadian Journal of Plant Science 52: 727-733.

Radhakrishnan, R. y Kumari, B.D.R. 2012. Pulsed magnetic field: A contemporary approach offers to enhance plant growth and yield of soybean. Plant Physiology and Biochemistry 51: 139-144.

Ruzic, R. y Jerman, I. 1998. Influence of $\mathrm{Ca}^{+2}$ in biological effect of direct and indirect ELF magnetic field simulation. Electro-and magnetobiology 17(2): 205-216.

Ruzic, R. y Jerman, I. 2002. Weak magnetic field decreases heat stress in cress seedlings. Electromagnetic Biology and Medicine 21: 69-80.

Savostin, P.W. 1930. Magnetic growth relations in plants. Planta 12: 327.

Shine, M.B., Guruprasad, K.N. y Anand, A. 2011. Enhancement of Germination, Growth, and Photosynthesis in Soybean by Pre-Treatment of Seeds with Magnetic Field. Bioelectromagnetics 32: 474-484.

Shiyan, L.T. 1978. Study on the ecological significance geomagnetic fields as an example of plants. SCI. Trans Kursk Teacher's Training College 191: 82-83.

Singh, P., Rai, K. y Rai, S. 1998. A short note on seedborne magnetic field on mustard (Brassica juncea, L.) crop. Electro- and Magnetobiology 17(a): 99-102.

Smith, S.D., McLeod, B.R. y Liboff, A.R. 1993. Effects of CR-tuned $60 \mathrm{~Hz}$ magnetic fields on sprouting and early growth of Raphanus sativus. Bioelectrochemistry and Bioenergetics Journal 32: 67-76.

Stern, D.P. 2001. La Tierra, el gran imán. http://www.phy6. org/earthmag/Mdmglist.htm. Consultado: 1 mayo de 2016.
Tagüeña, J. y Martina, E. 1997. La ciencia para todos. Editorial FCE, México D.F.

Tarduno, J.A., Cottrell, R.D., Watkeys, M.K., Hofmann, A., Doubrovine, P.V., E.E. Mamajek, D. Liu, D.G. Sibeck, L.P. Neukirch y Usui, Y. 2010. Geodynamo, solar wind, and magnetopause 3.4 to 3.45 billion years ago. Science 327: $1238-1240$.

Tipler, P. y Mosca, G. 2008. Electricidad y magnetismo. Luz. Física moderna. Reverté, Barcelona.

Torres, C., Díaz, J.E. y Cabal, P.A. 2008. Efecto de campos magnéticos en la germinación de semillas de arroz (Oryza sativa L.) y tomate (Solanum lycopersicum L.). Agronomía colombiana 26(2): 177-185.

Travkin, M.P. 1969. The Effect of Weak Magnetic Field on Seed Germination and Root Orientation. Proceedings Science Practice Conference. Belgorod Pedagogical Institute 5: 28-30.

Vakharia, D.N., Davariya, R.L. y Parameswaran, M. 1991. Influence of magnetic treatment on groundnut yield and yield attributes. Indian Journal of Plant Physiology 34(2): 131-136.

Vashisth, A. y Nagarajan, S. 2010. Effect on germination and early growth characteristics in sunflower (Helianthus annus) seeds exposed to static magnetic field. Journal of Plant Physiology 167(2): 149-156.

Vetrov, V.S., Gorbatsevich, N.A. y Stratskevich, L.K. 1989. Results of the use of growth simulating factors of plants in cultivation of maize in Belarus. Abstracts Conference The Use of Low Power Physical Factors in Biology and Agriculture 1:104-105.

Wood, R. 1991. Magnetismo. De la brújula a los imanes superconductores. Editorial McGraw-Hill, Serie de divulgación científica, Madrid.

Zúñiga, O., Benavides, J.A., Ospina-Salazar D.I., Jiménez, C.O. y Gutiérrez, M.A. 2016a. Tratamiento magnético de agua de riego y semillas en agricultura. Ingeniería y Competitividad 18 (2):217 - 232.

Zúñiga, O., Jiménez, C.O., Benavides, J.A. y Torres, C. 2016b. Effect of Electromagnetic Fields on Microbial Activity of a Bio-Fertilizer. Revista de Ciencias 20 (1):27-40.

Fecha de recepción: 18/02/2017

Fecha de aceptación: 05/09/2017

Publicado en línea: 14/09/2017

Para citar este artículo: Carbonell, M.V., Flórez, M., Martínez, E. y Álvarez, J. 2017. Aportaciones sobre el campo magnético: historia e influencia en sistemas biológicos. Intropica 12(2): 143-159. DOI: http://dx.doi.org/ 10.21676/23897864.2282 